\title{
Review Article \\ The Potential of MicroRNAs as Novel Biomarkers for Transplant Rejection
}

\author{
Matthias Hamdorf, Satoru Kawakita, and Matthew Everly \\ Terasaki Foundation Laboratory, 11570 W. Olympic Blvd., Los Angeles, CA 90064, USA \\ Correspondence should be addressed to Matthias Hamdorf; mhamdorf@terasakilab.org
}

Received 23 October 2016; Accepted 30 November 2016; Published 16 January 2017

Academic Editor: Senthamil Selvan

Copyright ( 2017 Matthias Hamdorf et al. This is an open access article distributed under the Creative Commons Attribution License, which permits unrestricted use, distribution, and reproduction in any medium, provided the original work is properly cited.

The control of gene expression by microRNAs (miRNAs, miR) influences many cellular functions, including cellular differentiation, cell proliferation, cell development, and functional regulation of the immune system. Recently, miRNAs have been detected in serum, plasma, and urine and circulating miR profiles have been associated with a variety of diseases. Rejection is one of the major causes of allograft failure and preventing and treating acute rejection are the central task for clinicians working with transplant patients. Invasive biopsies used in monitoring rejection are burdensome and risky to transplant patients. Novel and easily accessible biomarkers of acute rejection could make it possible to detect rejection earlier and make more fine-tuned calibration of immunosuppressive or new target treatment possible. In this review, we discuss whether circulating miRNA can serve as an early noninvasive diagnostic biomarker and an expression fingerprint of allograft rejection and transplant failure. Understanding the regulatory interplay of relevant miRNAs and the rejecting allograft will result in a better understanding of the molecular pathophysiology of alloimmune injury.

\section{Introduction}

MicroRNAMicroRNAs (miRNAs, miRs) are a class of small $(\sim 22 \mathrm{nt})$ noncoding molecules that inhibit translational initiation and stimulate decay of mRNA targets $[1,2]$. MiRs are transcribed by RNA polymerase II/III and processed by the RNAse III enzymes Drosha and its binding partner DGCR8 in the nucleus and Dicer in the cytoplasm, to produce short double-stranded RNAs. One strand of the doublestranded RNA is loaded into the Argonaute (Ago) protein and forms the miR-mediated silencing complex (miRISC). MiRs guide miRISC to pair with imperfect complementarity to sequences in target mRNAs, resulting in their subsequent destabilization and translational repression [3]. The target mRNA recognition by the miRISC is mediated by the "seed sequence" nucleotide 2 to $8[4,5]$. Recent data show that $35-$ $40 \%$ of miR binding sites are found in the $3^{\prime}$ UTRs, $40-50 \%$ in coding regions, and $<5 \%$ in the $5^{\prime} \mathrm{UTR}$ mRNA regions $[6,7]$. Greater than $60 \%$ of the human transcriptome is predicted to be under miR regulation, making this posttranscriptional control pathway as important as proteins in the regulation of cell functions [2]. It is clear that miRs play vital roles in regulating diverse functions in normal and diseased cells $[8$, 9]. Recent studies have shown that in addition to intracellular regulatory functions, miRs can be secreted and detected in bodily fluids such as blood and urine. The secreted miRs are associated with proteins (Ago2), lipoprotein complexes, or packaged into microvesicles like exosomes. Circulating miRNAs are very stable and resistant to treatment with ribonucleases, freezing/thawing cycles, and other drastic experimental conditions [10]. Several studies have shown that secreted miRNAs can function as a second messenger. MiRNAs packed into exosomes or HDL can be taken up as an active component by neighboring cells and induce cell modification/regulation [10,11]. The biogenesis, function, and export of miRNAs are shown in Figure 1. Recent reports have gone even further by reporting a much more complex picture of the strong regulatory functions of a diversity of other small ncRNA species such as piwi-interacting RNAs (piRNA) or long noncoding RNAs (lncRNA). PiRNA were 


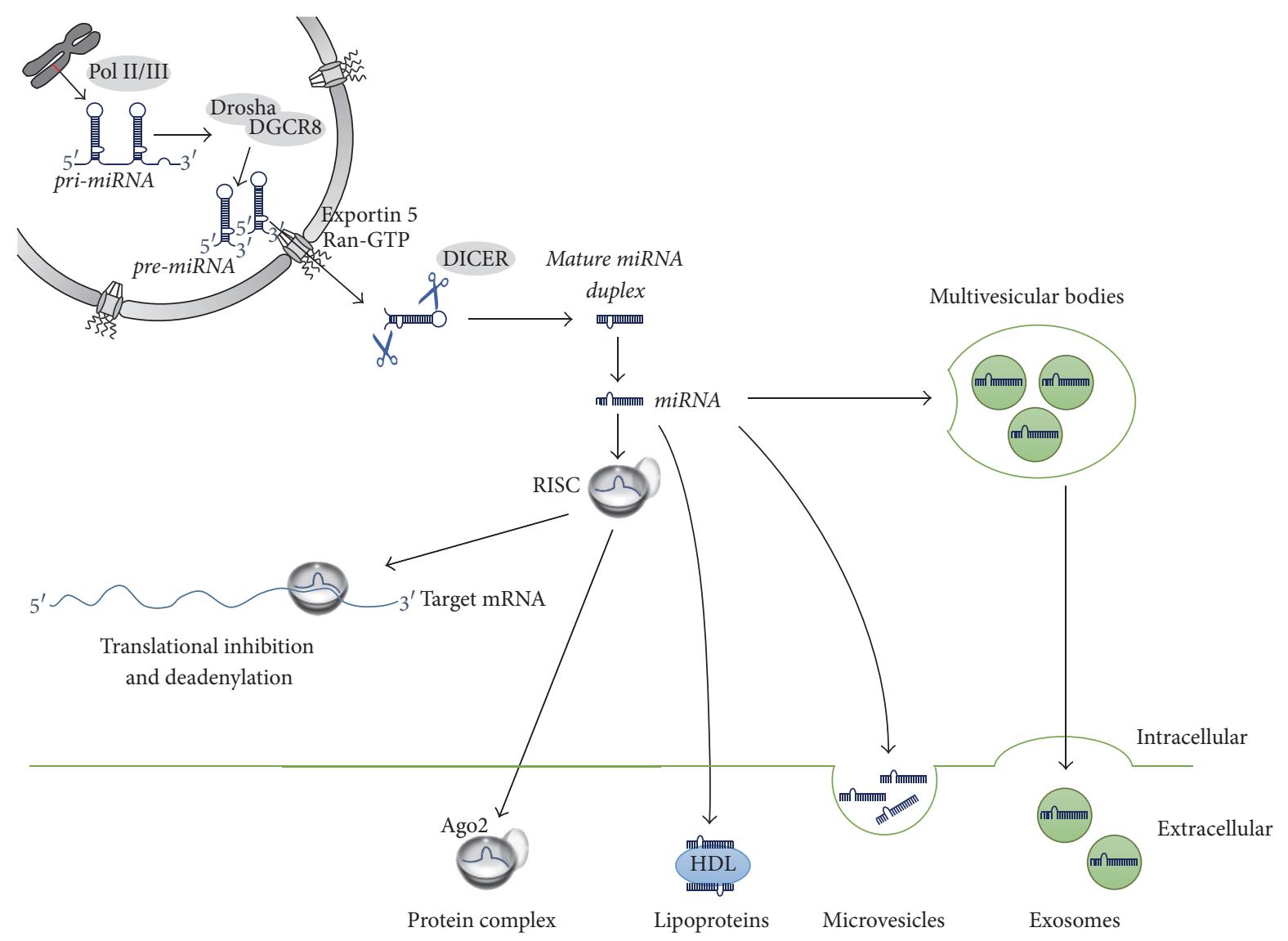

FIgURE 1: Biogenesis and release of miRNAs. Pri-miRNAs are transcribed in the nucleus by RNA polymerase II/III and processed by the ribonuclease Drosha into hairpin RNAs (pre-miRNA). The stem loops are exported into the cytoplasm using Exportin 5 and Ran-GTP and further cleaved by Dicer to yield 21-23 nucleotide duplexes. The duplexes are unwound and can be loaded directly into the RISC complex and guide translational repression of target mRNAs or they can be released from the cells in protein complexes, bound to lipoproteins, packed in microvesicles, or secreted in exosomes.

identified in germline cells as regulators of transposons. They depend on a specific PIWI clade protein and their biogenesis is independent of Dicer $[12,13]$. LncRNAs are a large and diverse class of transcribed RNA molecules with a length of more than 200 nucleotides that do not encode proteins. To date, very few lncRNAs have been characterized in detail. However, it is clear that lncRNAs are important regulators of gene expression and are thought to have a wide range of functions in cellular and developmental processes $[14,15]$. A short overview of selected RNA species and their functions is shown in Table 1. In summary, the identification of miRNAs and small RNA species seems to represent only the tip of the iceberg and the prediction of an individual miRNA; its target and function in health and disease are one of the big challenges in research.

\section{Use of miRNAs in Transplantation}

The few publications that exist on the topic of miRNAs and transplants focus on miRNAs isolated from biopsies. An overview of the different studies is given in Table 2. This review focuses on a short overview of the transplanted organ, the identified miRNA pattern, and shared common pathways.
TABLE 1: Categories, characteristics, and functions of selected ncRNAs.

\begin{tabular}{|c|c|c|}
\hline & Length & Function \\
\hline \multicolumn{3}{|c|}{ Short ncRNAs } \\
\hline miRNA & $\sim 22 \mathrm{nt}$ & $\begin{array}{l}\text { Posttranscriptional } \\
\text { regulation of gene } \\
\text { expression }\end{array}$ \\
\hline siRNA & $\sim 21 \mathrm{nt}$ & Gene silencing \\
\hline piRNA & $\sim 30 \mathrm{nt}$ & $\begin{array}{l}\text { Transposon } \\
\text { regulation, } \\
\text { development }\end{array}$ \\
\hline \multicolumn{3}{|c|}{ Long ncRNAs } \\
\hline rRNA & +1.9 kbases & $\begin{array}{c}\text { Protein } \\
\text { biosynthesis }\end{array}$ \\
\hline $\operatorname{lncRNA}$ & $\sim 200 \mathrm{nt}$ & $\begin{array}{l}\text { Epigenetics and } \\
\text { gene regulation }\end{array}$ \\
\hline
\end{tabular}

\section{1. miRNAs and Pathways Involved in Transplant Rejection}

2.1.1. TGF-Beta Signaling Pathway. An inflammatory reaction takes place during the acute or chronic rejection of 


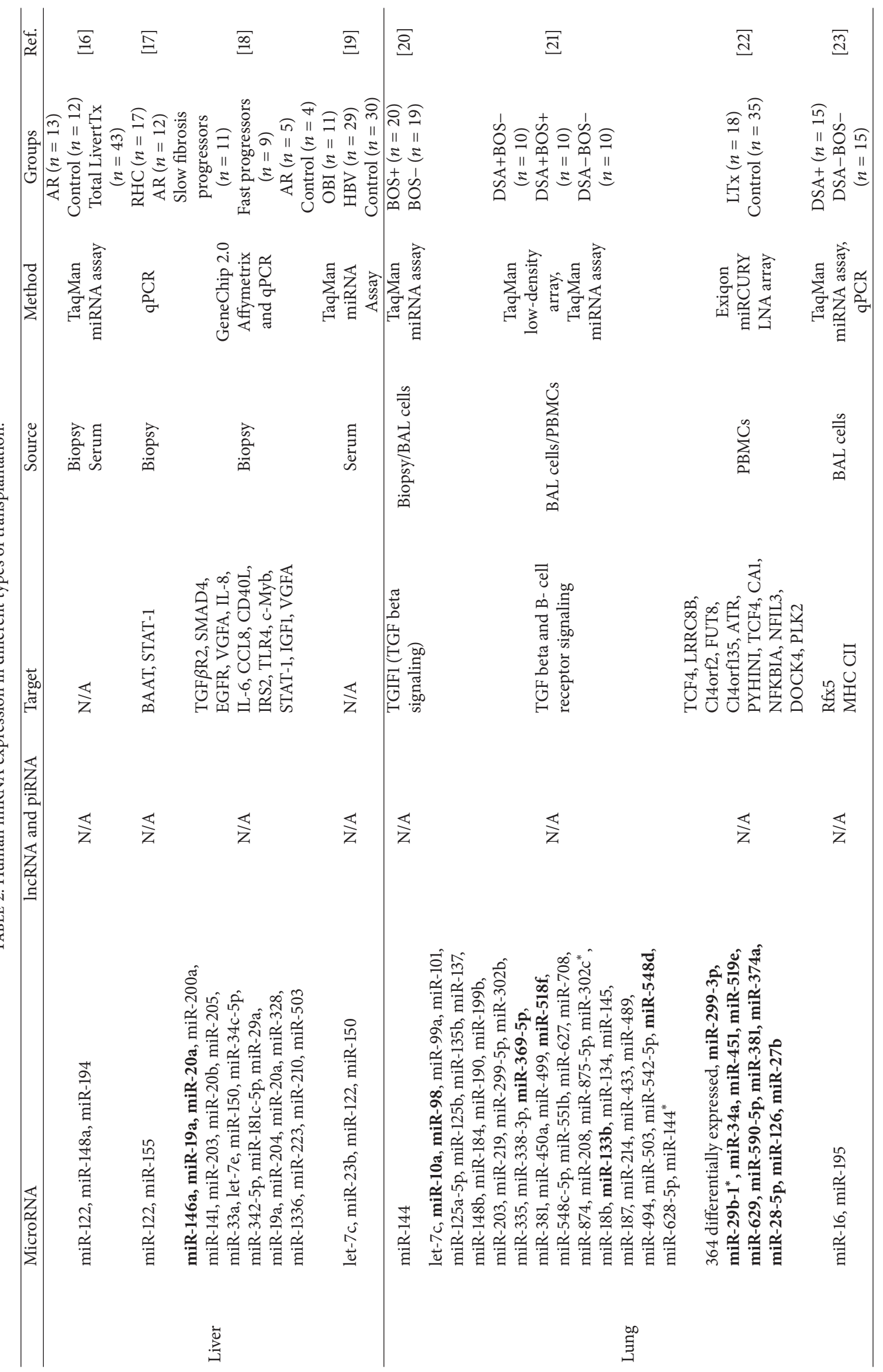




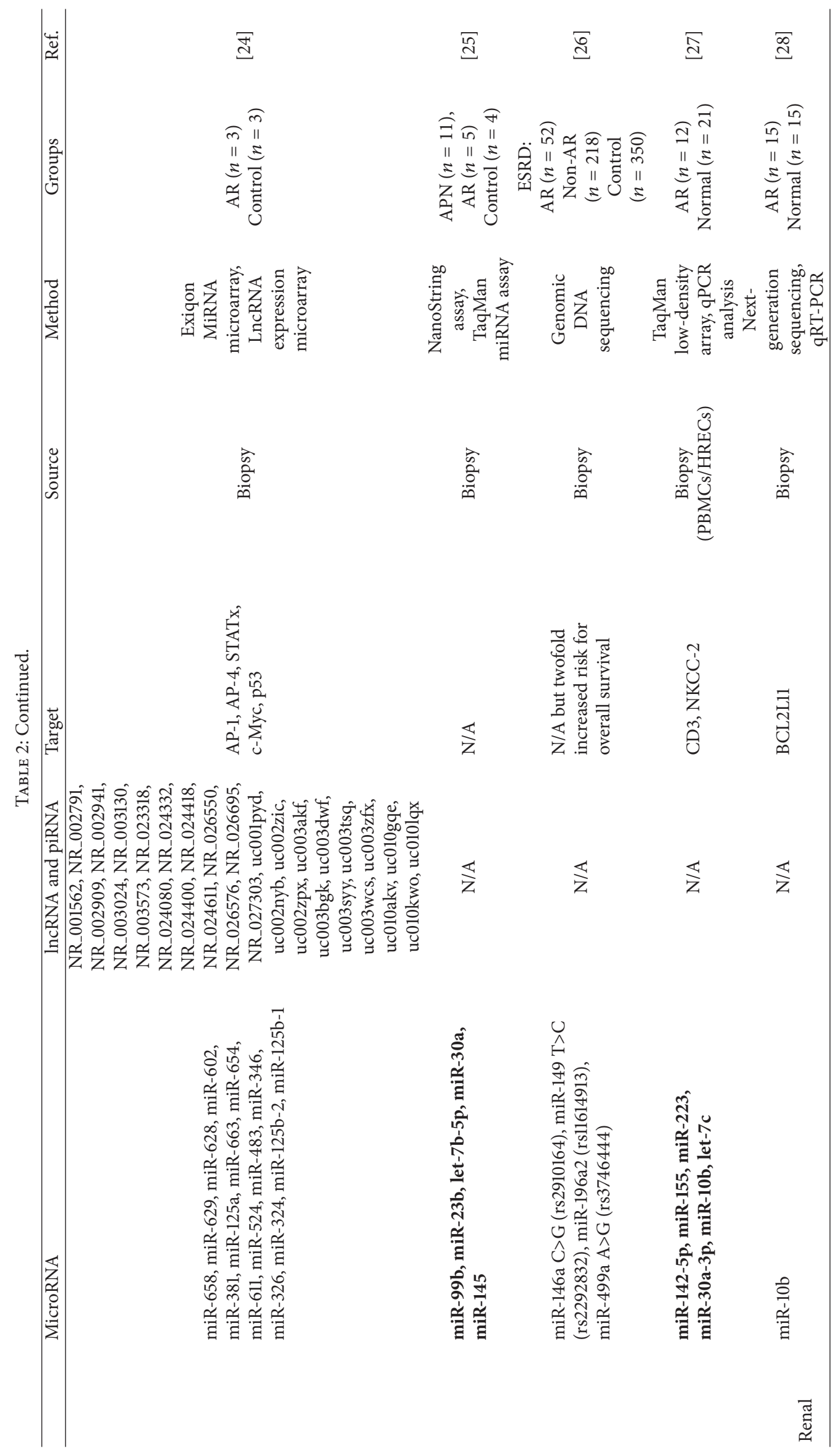




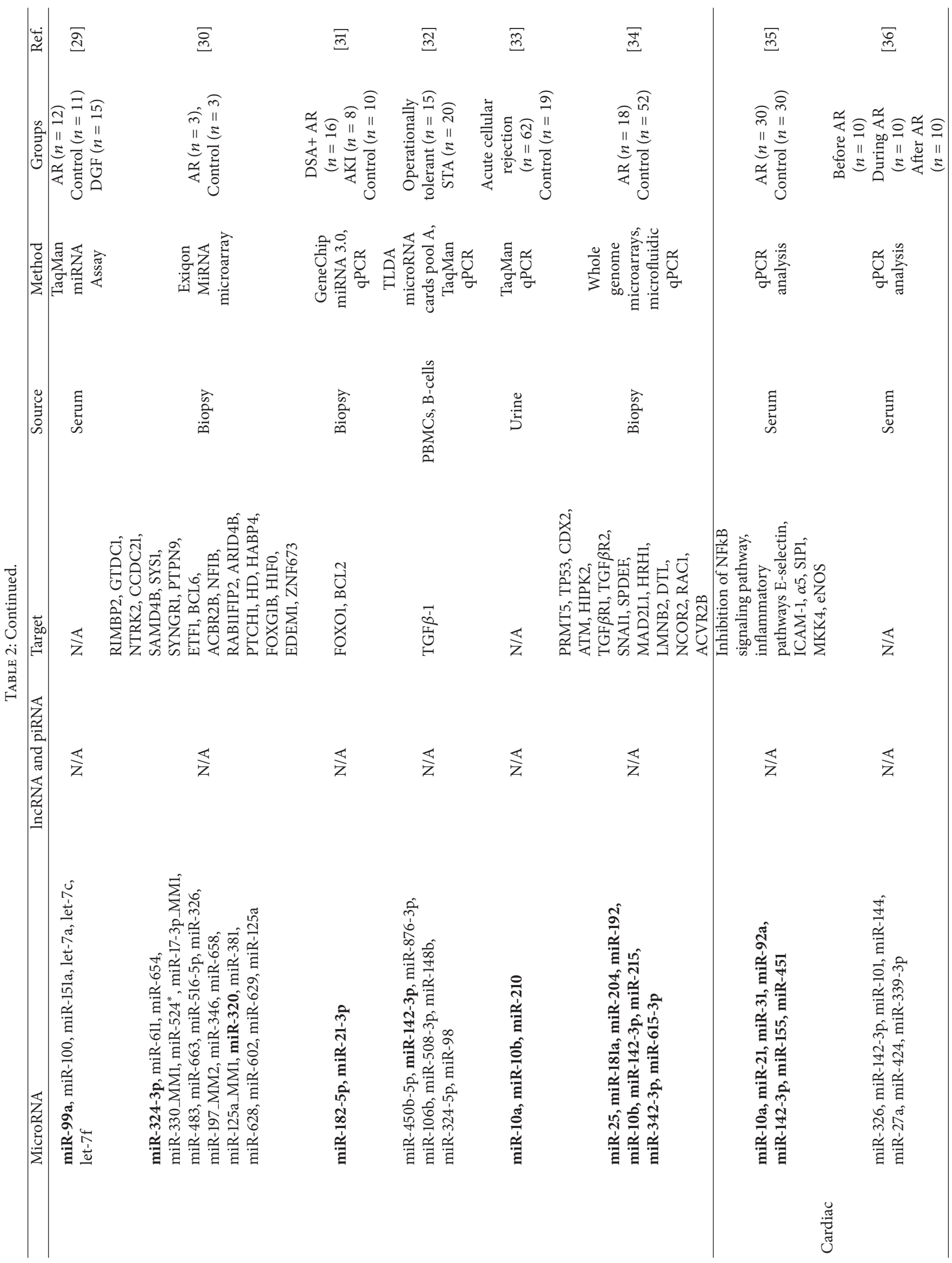




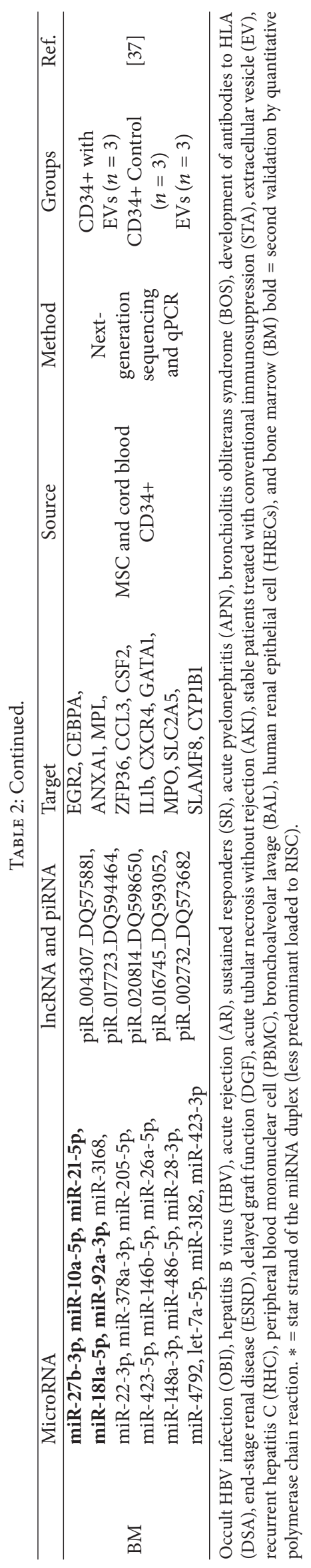


an organ. Among different cytokines such as IL-6 [38] and inflammatory mediators elicited during inflammation, TGF$\beta 1$ is considered the main mediator and inducer of fibrosis [39]. TGF- $\beta 1$ belongs to a family of growth factors that includes TGF- $\beta$ s, activins, and bone morphogenic proteins (BMPs). TGF- $\beta 1$ and BMP-7 are key determinant factors in peritoneal cell plasticity and in particular, the predominance of one or the other may determine the epithelial or mesenchymal phenotype [40,41]. Among the different organs and studies, the TGF-beta signaling pathway is the predominant pathway for organ rejection. Wilfingseder et al. (kidney) [42], Xu et al. (lung) [21], and Joshi et al. (liver) [18] described in their studies that miR-548d, miRNA-203, and miRNA-146a are regulators of SMAD4. After activation, SMAD4 forms homomeric and heteromeric complexes and translocates to the nucleus to initiate TGF-beta induced transcription. The downregulation of the miRNAs during rejection leads to an overexpression of SMAD4 and enhanced signaling. The receptor of TGF-beta (TGF $\beta$ R2) is regulated by miR-548d and miRNA-200a and miRNA-141 and downregulation leads to a higher density of the receptor on the cell surface. The miRNA-200 family is described in the literature as involved in inflammation and IL-6 regulation. In an additional publication, $\mathrm{Xu}$ et al. defined the role of miRNA144 in fibroproliferation leading to bronchiolitis obliterans syndrome (BOS) [20]. MiRNA-144 is strongly upregulated in BOS patients and downregulates TGIF1, a suppressor of TGFbeta induced transcription. The absence of the suppressor leads to an elevated production level of FGF, TGF-beta, and VEGF and promotes the onset of fibroses and organ rejection [20]. Discrimination of cases with fibrosis by miRNA profiles is certainly of interest in acute rejection as well as chronic rejection. The microRNA let-7c targets the TGF-beta and the WNT1 signaling pathway and can enhance the function of the other miRs [43]. In mouse transplantation models, it has been shown that miR-21 is one of the driving agents of fibrosis in acute cardiac allograft rejection [44]. In general, all miRs that are able to promote TGF-beta signaling and the development of fibrosis are drivers of rejection. The aforementioned publications lay out the mechanisms of miRNA and their function in the TGF-beta signaling pathways as a model for the interplay and modulation coursed by miRNAs.

2.1.2. T-Cell, B-Cell, and Macrophage Signaling and Development. Wilflingseder et al. showed that miR-182-5p expression is profoundly correlated with kidney tissue injury. MiR$182-5 p$ can be activated by IL- 2 and STAT5 and act as an inhibitor of FOXO1 expression. FOXO1 acts as a master cellular regulator of a variety of cellular processes including cell survival, apoptosis, proliferation, and metabolism. FOXO1 also plays a critical role in the homeostasis of cells of the immune system including T-cells, B-cells, and neutrophils [31]. Further, the absence of FOXO1 was shown to severely reduce the development of FOXP3+ regulatory T-cells $\left(\mathrm{T}_{\text {regs }}\right)$. Those $\mathrm{T}_{\text {regs }}$ that developed were found to be nonfunctional in vivo and downregulation of FOXO1 in T-cells resulted in lymphocyte infiltration and promotion of inflammation and immune response induced rejection of the transplant [45]. In addition, Wei et al. observed in their study that mice with rejecting cardiac allografts had significantly higher levels of miR-182 in the grafts, infiltrated mononuclear cells, and plasma compared to syngeneic transplants. These findings further support the potential of miRNAs as a biomarker for organ rejection [46]. One miRNA that has an overlap in three of the analyzed organs (see Figure 2) is let-7c. In the literature, let-7c is discussed as an important regulator of HSCs by controlling signaling of TGF-beta and WNT1 and plays a role in the development of $\mathrm{T}_{\mathrm{H}} 1$ cells [43]. Other publications show that the polarization and activation of macrophages are dependent on let-7c $[47,48]$. The development of $\mathrm{T}_{\mathrm{H}} 1$ cells in addition to the regulation of macrophages may play an important role in the recognition of the transplant and result in its rejection. Additionally, let-7c plays an important role in cardiomyogenesis [49] and may interfere with the replacement of tissue that is damaged by the immune system in heart transplants. Surprisingly, none of the cardiac tissue relevant miRs (miR-1, miR-133a, miR-208a/b, and miR-499) [50] are found to be affected by acute rejection. In particular for cardioprotection, a recent review discusses the importance of exosomes during normal health and injury and the interaction with the immune system [51].

$\mathrm{Xu}$ et al. found four differentially expressed miRNAs (miR-133b, miR-134, miR-433, and miR-628-5p) in the lungs that modulate the B-cell signaling pathway in different stages and regulate autoimmunity, immunoglobulin (Ig) production, and immune response. The study showed a significant downregulation of these miRNAs in donor specific antibody (DSA) positive BOS positive patients. The study argues that the downregulation leads to overactivation of the Bcell mediated immune response and to the DSA-induced rejection of the transplant [21].

\section{2. miRNAs as Potential Noninvasive Biomarkers for Acute and Chronic Rejection}

Liver. In many studies, miRNA-122 was discovered in mice and humans as a very liver-specific miRNA. In liver patients, it was demonstrated that hepatocyte-derived miRNAs miR122, miR-148a, and miR-194 correlated with hepatic injury and acute rejection after liver transplantation [16]. The serum level of these miRNAs was significantly increased in patients with liver injury induced by rejection and there was a strongly positive correlation with the clinically used aminotransferase diagnostic marker. Liu et al. discussed the findings in their study on the potential roles of the miR-148 family in immune homeostasis and regulation. When they examined dendritic cells (DCs) stimulated by TLR agonists, they discovered that the miRNA was overexpressed upon activation, which inhibited cytokine production, upregulation of MHC class II expression, and DC-mediated T-cell proliferation. They also observed that miR-148/152 targets calcium/calmodulindependent protein kinase II, which could increase production of proinflammatory cytokines in response to DC activation by TLR in mice [52]. Farid et al. were able to show that the miR-122 in the serum of patients with acute rejection reaches a high level even at the beginning of rejection in comparison with the classical aminotransferase marker and 


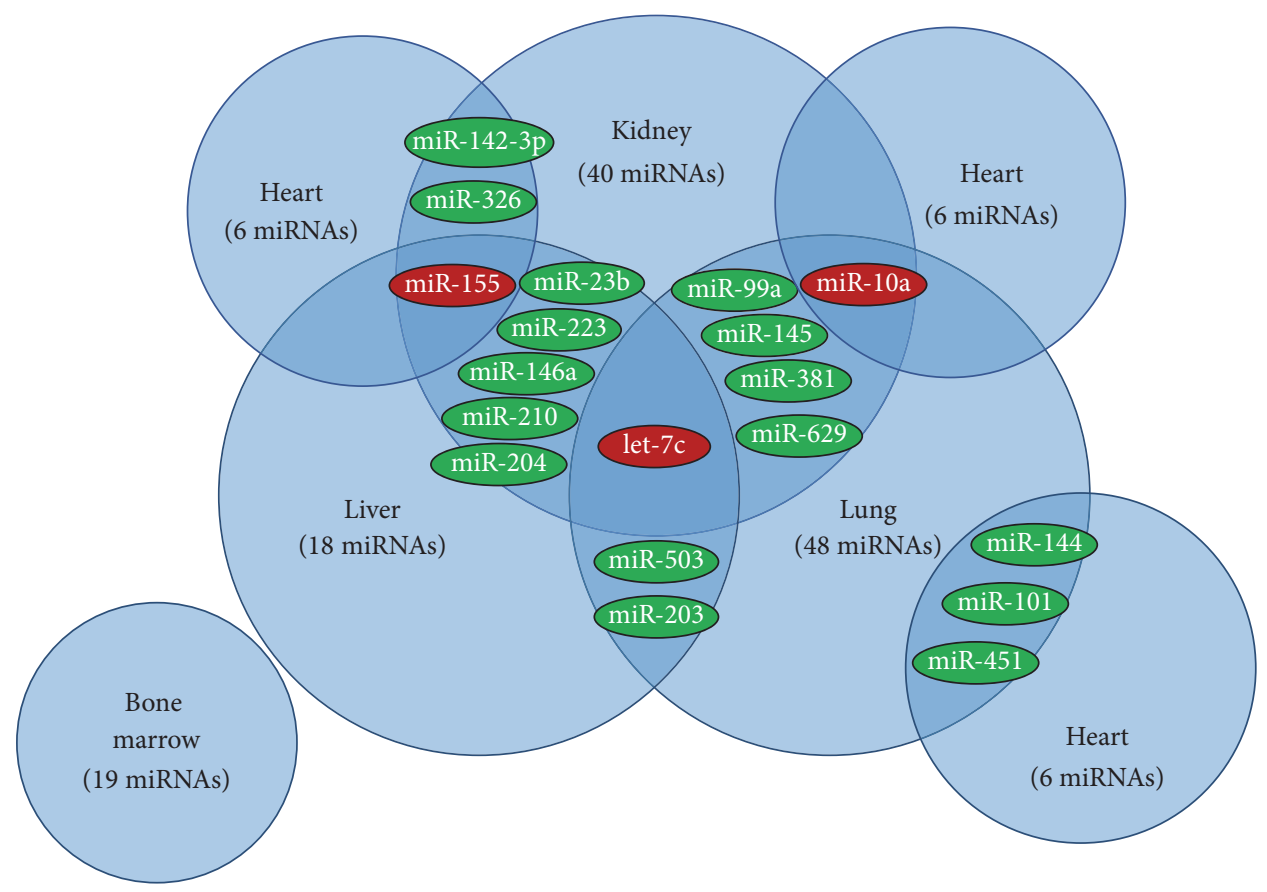

Red, shared by 3 organs

Green, shared by 2 organs

FIGURE 2: Comparison of overlapping miRs in the different studies. Color-labeled miRs indicate a miRNA shared by 2 (green) and 3 (red) organs, respectively. The number in parentheses represents nonoverlapping miRNAs detected for the corresponding organ.

may perhaps provide a new marker for early diagnosis and faster intervention during an acute liver rejection [16]. The significance of miRNA in liver transplant rejection has also been supported by animal studies conducted by Morita et al. They investigated the miRNAs involved in acute rejection of liver allografts in mice and found that miR-146a, 15b, 223, 23a, 27a, 34a, and 451 were significantly increased in the grafts while miR-101a, 101b, and 148a decreased in their expression levels [53]. Several studies have quantified circulating miRNAs as potential biomarkers for hepatitis B (HBV) and hepatitis C (HCV) infections and identified four that are differentially expressed between HBV and control groups (let-7c, miR-23b, miR-122, and miR-150) [19, 54]. HCV infection studies found a significant increase of miR21 [55-57], and this finding may be translated into transplant studies as well. In summary, miR-122 in combination with other miRNAs seems to be a good diagnostic marker for rejection.

As a novel diagnostic marker miRNAs in exosomes can be a sensor for injury and inflammation. Bala et al. studied several miRNAs packed in exosomes of liver disease patients and they were able to identify a specific pattern of miRNA reflecting liver injury [58].

Lung. Guo et al. found tissue-specific miR-126 to be a lung marker [59]. Zhang et al. identified miR-126 after lung transplantation when they analyzed peripheral blood mononuclear cells [22]. In mice, it has been reported that miR-126 is highly expressed by plasmacytoid DCs and it regulates the survival and function of these cells. Moreover, this miRNA was shown to regulate production of type 1 Interferon by controlling expression of KDR that encodes VEGF-receptor 2 [60]. It is unclear if this is a contamination of lung cells during the preparation or if this is due to the fact that lung tissue is damaged after lung transplantation. There is a huge variety among the detected miRNA profiles during lung rejection and even studies using the same parameters such as DSA+ and/or BOS+ end up with no significant overlap in the miRNA profiles. Further investigation is needed to define a specific marker for lung injury.

Renal. The greatest number of miRNA and transplant studies is done in renal transplantations. The kidney specific miRNA146a seems to be a risk factor in development of rejection because as Misra et al. were able to demonstrate, the mutation in miR-146 (SNP) is associated with double the risk for rejection [26]. MiRNA-146a expression is highly elevated in response to inflammatory stimuli such as cytokines. Specifically, a recent study on miRNA expression in human activated CD8+ T-cells showed that when these cells were treated with IL-2 or IL-15, miR-146a was significantly upregulated. Also, they were able to demonstrate that subsets of CD8+ T-cells, including naïve and memory cells, differentially expressed certain miRNAs, with 146a being strongly upregulated in the memory T-cell subset [61, 62]. MiR-10b is another kidney specific miRNA that regulates the expression of BCL2L11. Downregulation of miR-10b directly depressed the expression of BCL2L11. Transfecting miR-10b into human renal 
glomerular endothelial cells recapitulated key features of acute allograft rejection, including endothelial cell apoptosis, release of pro/inflammatory cytokines (IL-6, TNF-alpha, IFN-gamma, and CCL2) and chemotaxis of macrophages, whereas transfection of miR-10b mimics had the opposite effects [28]. Members of the miR-10 cluster were also found in other organ transplantation studies. Despite the numerous studies in kidney transplantation, there is no common marker for acute rejection and further investigation to find a marker for clinical use is necessary. Sui et al. investigated mechanisms that are related to rejection by integrating protein, mRNA, miRNA, and lncRNA in biopsies of patients with acute rejection versus controls. They were able to predict five transcription factors that are active and responsible for rejection and these transcription factors correlate with 12 miRNAs and 32 lncRNAs. In a previous study, the same author was able to confirm and validate two additional miRNAs (miR-320 and miR-324) by quantitative polymerase chain reaction [24].

Cardiac. Many studies describe miRNA-142-3p as an expression marker of organ grafts. It is associated with lymphocyte alloimmunity during rejection and organ damage. This miRNA is found as an overlap in the three presented studies of heart transplantation $[32,34,35]$. Van Huyen et al. identified and validated a set of four miRNAs (miR-10a, miR-31, miR92a, and miR-155) as a specific signature for cardiac rejection. The correlation in the receiver operating curves showed a very strong and significant relationship between these miRNAs and rejection [35]. In different studies, miR-10b has been shown as an inhibitor of NFkB signaling and as a regulator of the proinflammatory markers MCP-1, IL-6, IL-8, IL-1, and VCAM [63]. For miRNA-155, Liod et al. described several inflammatory functions that include its enhanced expression after activation of the T-cell receptor, the repression of the IFN receptor, and the contribution to Ig class switch in B cells. Increased expression of this miRNA molecule is also associated with activation of DCs. MiRNA-155 is believed to possess the ability to modulate the antigen presentation activity of DCs to activate T-cells according to animal studies using a mouse model [64]. In DCs derived from human monocytes, following activation by lipopolysaccharides, the expression of miRNA-155 was upregulated as high as 50fold. In the same study, the knockout of miR-155 in the activated DCs led to an increase in some cytokine gene expression, suggesting its potential role as a negative regulator of cytokine production [65]. Moreover, miR-155 has been found to be upregulated in graft infiltrating lymphocytes, T-cells in spleen, and circulating lymphocytes during acute cardiac rejection in mice. GSK $3 \beta$ was identified to be a direct target of miR-155, which decreased GSK $3 \beta$ expression and thereby increased proliferation of T-cells [66]. MiRNA-31 mainly regulates the expression of E-selectin and ICAM-1 when it is induced by the TNF pathway. It also regulates the infiltration of immune cells into the tissue. Finally, miR92 targets integrin $\alpha 5, \mathrm{~S} 1 \mathrm{P} 1, \mathrm{MKK} 4$, and eNOS and plays a potentially important role in the vascular inflammatory response. Dawi et al. discovered three miRNAs, miR-326, miR-142-3p, and miR-101, which have crucial functions in the regulation and maintenance of self-tolerance. Further investigation of miR-142-3p in combination with an miRNA that shows organ damage could prove to be a good candidate biomarker for ongoing rejection.

More systematical research is needed to determine whether miRNAs can be applied as biomarkers, therapeutic targets, or therapeutic agents for specific organs. For other inflammatory diseases like atherosclerosis, a full network between miRNA, organs, and immune cells are described and can help to understand the function in an ongoing inflammation that can lead to chronic rejection [67]. As additional information, a great overview about organ-specific miRNAs as a potential profile for allo- and xenotransplantation is given in the review from Zhou et al. [68].

2.3. miRNAs as a Tool to Enhance Transplantation. The last study we would like to discuss in this review is a study that was done in hematopoietic stem cell (HSC) transplantation and that shows the positive effect of miRNAs packaged in extracellular vesicles on HSC transplantation. De Luca et al. identified miRNAs and piRNA derived from extracellular vesicles (EVs) secreted by mesenchymal stem cells. The group found 87 miRNAs and five piRNAs differentially expressed and predicted to regulate cell differentiation and apoptosis. Validation of four miRNAs and further experiments showed that the EV treatment of HSCs enhances host engraftment and HSC plasticity and function. These findings create a new perspective on how miRNA and piRNA in EVs can positively influence the outcome of transplantations [37].

In addition to this study several publications are showing a specific regulatory function of exosomes and the proteins and miRNAs transmitted by them. As an example Song et al. were able to show that donor-derived peripheral exosomes have the potential to inhibit immune inflammation in allograft heart transplantation by the specific induction of Treg cells [69]. For microvesicle-delivered miRNAs derived from endothelial progenitor cells, it was demonstrated that they are able to reprogram residential renal cells and protect the kidney from ischemia-reperfusion injury [70]. The review from Monguió-Tortajada et al. gives a great overview of the variety of these regulatory functions, from classical immunosuppression to novel extracellular vesicles [71].

\section{Conclusion}

MiRNAs are emerging as important regulatory molecules of gene expression. They play a significant role in many physiological and pathological processes and have revolutionized cellular biology in the past decade. Research has focused on different expression profiles in health and disease. In the field of transplantation, several miRNAs have been described and it has been shown that miRs have the potential to be a novel diagnostic marker. Therefore, they represent a group of promising candidates for early detection of organ rejection with the potential to affect clinical decision making. However, further investigation and standardization in the profiling of miRNAs in serum, plasma, and urine samples are needed to find a robust diagnostic marker and to develop insights into pathways responsible for the rejection process as well as novel targets for therapy. A few miRNA mimics (miR-34 in phase I) 
and miRNA inhibitors (anti-miR-122 in phase II) are already in their first clinical trials and show promising results in $\mathrm{HCV}$ and primary liver cancer treatment $[72,73]$. Today we are on the verge of implementing many of these new technologies into the clinical routine to improve diagnosis and treatment of transplant patients and to enhance their quality of life.

\section{Competing Interests}

The authors declare that they have no competing interests.

\section{Acknowledgments}

Thanks go to all Terasaki Foundation members for their support and we offer special thanks to Judy Hopfield, Bach Tran, and Kellyann Everly for looking over the manuscript several times.

\section{References}

[1] M. Chekulaeva and W. Filipowicz, "Mechanisms of miRNAmediated post-transcriptional regulation in animal cells," Current Opinion in Cell Biology, vol. 21, no. 3, pp. 452-460, 2009.

[2] D. P. Bartel, "MicroRNAs: genomics, biogenesis, mechanism, and function," Cell, vol. 116, no. 2, pp. 281-297, 2004.

[3] R. C. Friedman, K. K.-H. Farh, C. B. Burge, and D. P. Bartel, "Most mammalian mRNAs are conserved targets of microRNAs," Genome Research, vol. 19, no. 1, pp. 92-105, 2009.

[4] P. Sood, A. Krek, M. Zavolan, G. Macino, and N. Rajewsky, "Cell-type-specific signatures of microRNAs on target mRNA expression," Proceedings of the National Academy of Sciences of the United States of America, vol. 103, no. 8, pp. 2746-2751, 2006.

[5] D. P. Bartel, "MicroRNAs: target recognition and regulatory functions," Cell, vol. 136, no. 2, pp. 215-233, 2009.

[6] D. G. Zisoulis, M. T. Lovci, M. L. Wilbert et al., "Comprehensive discovery of endogenous Argonaute binding sites in Caenorhabditis elegans," Nature Structural \& Molecular Biology, vol. 17, no. 2, pp. 173-179, 2010.

[7] G. B. Loeb, A. A. Khan, D. Canner et al., "Transcriptomewide miR-155 binding map reveals widespread noncanonical microRNA targeting," Molecular Cell, vol. 48, no. 5, pp. 760770, 2012.

[8] D. Sayed and M. Abdellatif, "Micrornas in development and disease," Physiological Reviews, vol. 91, no. 3, pp. 827-887, 2011.

[9] B. D. Adams, A. L. Kasinski, and F. J. Slack, "Aberrant regulation and function of microRNAs in cancer," Current Biology, vol. 24, no. 16, pp. R762-R776, 2014.

[10] C. Guay and R. Regazzi, "Circulating microRNAs as novel biomarkers for diabetes mellitus," Nature Reviews Endocrinology, vol. 9, no. 9, pp. 513-521, 2013.

[11] J. Zhang, S. Li, L. Li et al., "Exosome and exosomal microRNA: trafficking, sorting, and function," Genomics, Proteomics \& Bioinformatics, vol. 13, no. 1, pp. 17-24, 2015.

[12] A. A. Aravin, R. Sachidanandam, A. Girard, K. Fejes-Toth, and G. J. Hannon, "Developmentally regulated piRNA clusters implicate MILI in transposon control," Science, vol. 316, no. 5825, pp. 744-747, 2007.

[13] M. Halic and D. Moazed, "Transposon silencing by piRNAs," Cell, vol. 138, no. 6, pp. 1058-1060, 2009.
[14] J. E. Wilusz, H. Sunwoo, and D. L. Spector, "Long noncoding RNAs: functional surprises from the RNA world," Genes \& Development, vol. 23, no. 13, pp. 1494-1504, 2009.

[15] V. J. Peschansky and C. Wahlestedt, "Non-coding RNAs as direct and indirect modulators of epigenetic regulation," Epigenetics, vol. 9, no. 1, pp. 3-12, 2014.

[16] W. R. R. Farid, Q. Pan, A. J. P. Van Der Meer et al., "Hepatocytederived microRNAs as serum biomarkers of hepatic injury and rejection after liver transplantation," Liver Transplantation, vol. 18, no. 3, pp. 290-297, 2012.

[17] T. Asaoka, D. Hernandez, P. Tryphonopoulos et al., "Clinical significance of intragraft miR-122 and -155 expression after liver transplantation," Hepatology Research, vol. 45, no. 8, pp. 898905, 2015.

[18] D. Joshi, S. Salehi, H. Brereton et al., "Distinct microRNA profiles are associated with the severity of hepatitis $C$ virus recurrence and acute cellular rejection after liver transplantation," Liver Transplantation, vol. 19, no. 4, pp. 383-394, 2013.

[19] Y. Chen, L. Li, Z. Zhou, N. Wang, C.-Y. Zhang, and K. Zen, "A pilot study of serum microRNA signatures as a novel biomarker for occult hepatitis B virus infection," Medical Microbiology and Immunology, vol. 201, no. 3, pp. 389-395, 2012.

[20] Z. Xu, S. Ramachandran, M. Gunasekaran et al., "MicroRNA144 dysregulates the transforming growth factor- $\beta$ signaling cascade and contributes to the development of bronchiolitis obliterans syndrome after human lung transplantation," The Journal of Heart and Lung Transplantation, vol. 34, no. 9, pp. 1154-1162, 2015.

[21] Z. Xu, D. Nayak, W. Yang et al., "Dysregulated MicroRNA expression and chronic lung allograft rejection in recipients with antibodies to donor HLA," American Journal of Transplantation, vol. 15, no. 7, pp. 1933-1947, 2015.

[22] W. Zhang, T. Zhou, S. F. Ma, R. F. Machado, S. M. Bhorade, and J. G. Garcia, "MicroRNAs implicated in dysregulation of gene expression following human lung transplantation," Translational Respiratory Medicine, vol. 1, no. 1, article 12, 2013.

[23] Z. Xu, D. K. Nayak, N. Benshoff, R. Hachem, A. E. Gelman, and T. Mohanakumar, "De novo-developed antibodies to donor MHC antigens lead to dysregulation of microRNAs and induction of MHC class II," The Journal of Immunology, vol. 194, no. 12, pp. 6133-6143, 2015.

[24] W. Sui, H. Lin, W. Peng et al., "Molecular dysfunctions in acute rejection after renal transplantation revealed by integrated analysis of transcription factor, microRNA and long noncoding RNA," Genomics, vol. 102, no. 4, pp. 310-322, 2013.

[25] S. Oghumu, A. Bracewell, U. Nori et al., "Acute pyelonephritis in renal allografts-a new role for microRNAs?" Transplantation, vol. 97, no. 5, pp. 559-568, 2014.

[26] M. K. Misra, S. K. Pandey, R. Kapoor, R. K. Sharma, and S. Agrawal, "Genetic variants of MicroRNA-related genes in susceptibility and prognosis of end-stage renal disease and renal allograft outcome among north Indians," Pharmacogenetics and Genomics, vol. 24, no. 9, pp. 442-450, 2014.

[27] D. Anglicheau, V. K. Sharma, R. Ding et al., "MicroRNA expression profiles predictive of human renal allograft status," Proceedings of the National Academy of Sciences of the United States of America, vol. 106, no. 13, pp. 5330-5335, 2009.

[28] X. Liu, C. Dong, Z. Jiang et al., "MicroRNA-10b downregulation mediates acute rejection of renal allografts by derepressing BCL2L11," Experimental Cell Research, vol. 333, no. 1, pp. 155163, 2015. 
[29] J. Tao, X. Yang, Z. Han et al., "Serum MicroRNA-99a helps detect acute rejection in renal transplantation," Transplantation Proceedings, vol. 47, no. 6, pp. 1683-1687, 2015.

[30] W. Sui, Y. Dai, Y. Huang, H. Lan, Q. Yan, and H. Huang, "Microarray analysis of MicroRNA expression in acute rejection after renal transplantation," Transplant Immunology, vol. 19, no. 1, pp. 81-85, 2008.

[31] J. Wilflingseder, J. Sunzenauer, E. Toronyi et al., "Molecular pathogenesis of post-transplant acute kidney injury: assessment of whole-genome mRNA and miRNA profiles," PLoS ONE, vol. 9, no. 8, Article ID e104164, 2014.

[32] R. Danger, A. Pallier, M. Giral et al., "Upregulation of miR-142$3 p$ in peripheral blood mononuclear cells of operationally tolerant patients with a renal transplant," Journal of the American Society of Nephrology, vol. 23, no. 4, pp. 597-606, 2012.

[33] J. M. Lorenzen, I. Volkmann, J. Fiedler et al., "Urinary miR-210 as a mediator of acute T-cell mediated rejection in renal allograft recipients," American Journal of Transplantation, vol. 11, no. 10, pp. 2221-2227, 2011.

[34] M. J. Vitalone, T. K. Sigdel, N. Salomonis, R. D. Sarwal, S.C. Hsieh, and M. M. Sarwal, "Transcriptional perturbations in graft rejection,” Transplantation, vol. 99, no. 9, pp. 1882-1893, 2015.

[35] J.-P. D. Van Huyen, M. Tible, A. Gay et al., "MicroRNAs as noninvasive biomarkers of heart transplant rejection," European Heart Journal, vol. 35, no. 45, pp. 3194-3202, 2014.

[36] I. Sukma Dewi, K. Torngren, O. Gidlöf, B. Kornhall, and J. Öhman, "Altered serum miRNA profiles during acute rejection after heart transplantation: potential for non-invasive allograft surveillance," Journal of Heart and Lung Transplantation, vol. 32, no. 4, pp. 463-466, 2013.

[37] L. De Luca, S. Trino, I. Laurenzana et al., "MiRNAs and piRNAs from bone marrow mesenchymal stem cell extracellular vesicles induce cell survival and inhibit cell differentiation of cord blood hematopoietic stem cells: a new insight in transplantation," Oncotarget, vol. 7, no. 6, pp. 6676-6692, 2015.

[38] J. Scheller, A. Chalaris, D. Schmidt-Arras, and S. Rose-John, "The pro- and anti-inflammatory properties of the cytokine interleukin-6," Biochimica et Biophysica Acta-Molecular Cell Research, vol. 1813, no. 5, pp. 878-888, 2011.

[39] X. Meng, D. J. Nikolic-Paterson, and H. Y. Lan, “TGF- $\beta$ : the master regulator of fibrosis," Nature Reviews Nephrology, vol. 12, no. 6, pp. 325-338, 2016.

[40] S. Piera-Velazquez, Z. Li, and S. A. Jimenez, "Role of endothelial-mesenchymal transition (EndoMT) in the pathogenesis of fibrotic disorders," American Journal of Pathology, vol. 179, no. 3, pp. 1074-1080, 2011.

[41] M. T. Pinto, D. T. Covas, S. Kashima, and C. O. Rodrigues, "Endothelial mesenchymal transition: comparative analysis of different induction methods," Biological Procedures Online, vol. 18, article 10, 2016.

[42] J. Wilflingseder, R. Reindl-Schwaighofer, J. Sunzenauer et al., "MicroRNAs in kidney transplantation," Nephrology Dialysis Transplantation, vol. 30, no. 6, pp. 910-917, 2015.

[43] A. Mehta and D. Baltimore, "MicroRNAs as regulatory elements in immune system logic," Nature Reviews Immunology, vol. 16, no. 5, pp. 279-294, 2016.

[44] S. K. Gupta, R. Itagaki, X. Zheng et al., "miR-21 promotes fibrosis in an acute cardiac allograft transplantation model," Cardiovascular Research, vol. 110, no. 2, pp. 215-226, 2016.
[45] W. Ouyang, W. Liao, C. T. Luo et al., "Novel Foxol-dependent transcriptional programs control $\mathrm{T}_{\text {reg }}$ cell function," Nature, vol. 491, no. 7425, pp. 554-559, 2012.

[46] L. Wei, M. Wang, X. Qu et al., "Differential expression of microRNAs during allograft rejection," American Journal of Transplantation, vol. 12, no. 5, pp. 1113-1123, 2012.

[47] S. Banerjee, N. Xie, H. Cui et al., "MicroRNA let-7c regulates macrophage polarization," Journal of Immunology, vol. 190, no. 12, pp. 6542-6549, 2013.

[48] W. Zhang, H. Liu, W. Liu, Y. Liu, and J. Xu, "Polycomb-mediated loss of microRNA let-7c determines inflammatory macrophage polarization via PAK1-dependent NF- $\kappa \mathrm{B}$ pathway," Cell Death and Differentiation, vol. 22, no. 2, pp. 287-297, 2015.

[49] A. Coppola, A. Romito, C. Borel et al., "Cardiomyogenesis is controlled by the miR-99a/let-7c cluster and epigenetic modifications," Stem Cell Research, vol. 12, no. 2, pp. 323-337, 2014.

[50] D. A. Chistiakov, A. N. Orekhov, and Y. V. Bobryshev, "Cardiacspecific miRNA in cardiogenesis, heart function, and cardiac pathology (with focus on myocardial infarction)," Journal of Molecular and Cellular Cardiology, vol. 94, pp. 107-121, 2016.

[51] L. Barile, T. Moccetti, E. Marbán, and G. Vassalli, "Roles of exosomes in cardioprotection," European Heart Journal, Article ID ehw304, 2016.

[52] X. Liu, Z. Zhan, L. Xu et al., "MicroRNA-148/152 impair innate response and antigen presentation of TLR-triggered dendritic cells by targeting CaMKII $\alpha$," Journal of Immunology, vol. 185, no. 12, pp. 7244-7251, 2010.

[53] M. Morita, J. Chen, M. Fujino et al., "Identification of microRNAs involved in acute rejection and spontaneous tolerance in murine hepatic allografts," Scientific Reports, vol. 4, article no. 6649, pp. 1-11, 2014.

[54] H.-X. Fan and H. Tang, "Complex interactions between microRNAs and hepatitis B/C viruses," World Journal of Gastroenterology, vol. 20, no. 37, pp. 13477-13492, 2014.

[55] Y. Chen, J. Chen, H. Wang et al., "HCV-induced miR-21 contributes to evasion of host immune system by targeting MyD88 and IRAK1," PLoS Pathogens, vol. 9, no. 4, Article ID e1003248, 2013.

[56] C. H. Lee, J. H. Kim, and S.-W. Lee, "The role of microRNAs in hepatitis $\mathrm{C}$ virus replication and related liver diseases," Journal of Microbiology, vol. 52, no. 6, pp. 445-451, 2014.

[57] S. Shrivastava, R. Steele, R. Ray, and R. B. Ray, "MicroRNAs: role in hepatitis C virus pathogenesis," Genes \& Diseases, vol. 2, no. 1, pp. 35-45, 2015.

[58] S. Bala, J. Petrasek, S. Mundkur et al., "Circulating microRNAs in exosomes indicate hepatocyte injury and inflammation in alcoholic, drug-induced, and inflammatory liver diseases," Hepatology, vol. 56, no. 5, pp. 1946-1957, 2012.

[59] Z. Guo, M. Maki, R. Ding, Y. Yang, B. Zhang, and L. Xiong, "Genome-wide survey of tissue-specific microRNA and transcription factor regulatory networks in 12 tissues," Scientific Reports, vol. 4, article 5150, 2014.

[60] J. Agudo, A. Ruzo, N. Tung et al., “The miR-126-VEGFR2 axis controls the innate response to pathogen-associated nucleic acids," Nature Immunology, vol. 15, no. 1, pp. 54-62, 2014.

[61] H. M. Sheppard, D. Verdon, A. E. Brooks et al., "MicroRNA regulation in human CD8+ T cell subsets-cytokine exposure alone drives miR-146a expression," Journal of Translational Medicine, vol. 12, article no. 292, 2014.

[62] L.-F. Lu, M. P. Boldin, A. Chaudhry et al., "Function of miR-146a in controlling Treg cell-mediated regulation of Th1 responses," Cell, vol. 142, no. 6, pp. 914-929, 2010. 
[63] Y. Fang, C. Shi, E. Manduchi, M. Civelek, and P. F. Davies, "MicroRNA-10a regulation of proinflammatory phenotype in athero-susceptible endothelium in vivo and in vitro," Proceedings of the National Academy of Sciences of the United States of America, vol. 107, no. 30, pp. 13450-13455, 2010.

[64] L. A. Smyth, D. A. Boardman, S. L. Tung, R. Lechler, and G. Lombardi, "MicroRNAs affect dendritic cell function and phenotype," Immunology, vol. 144, no. 2, pp. 197-205, 2015.

[65] M. Ceppi, P. M. Pereira, I. Dunand-Sauthier et al., "MicroRNA155 modulates the interleukin-1 signaling pathway in activated human monocyte-derived dendritic cells," Proceedings of the National Academy of Sciences of the United States of America, vol. 106, no. 8, pp. 2735-2740, 2009.

[66] Z. Feng, Y. Xia, M. Zhang, and J. Zheng, "MicroRNA-155 regulates $\mathrm{T}$ cell proliferation through targeting GSK3 $\beta$ in cardiac allograft rejection in a murine transplantation model," Cellular Immunology, vol. 281, no. 2, pp. 141-149, 2013.

[67] M. W. Feinberg and K. J. Moore, "MicroRNA regulation of atherosclerosis," Circulation Research, vol. 118, no. 4, pp. 703720, 2016.

[68] M. Zhou, H. Hara, Y. Dai et al., "Circulating organ-specific MicroRNAs serve as biomarkers in organ-specific diseases: implications for organ Allo- and Xeno-transplantation," International Journal of Molecular Sciences, vol. 17, no. 8, p. 1232, 2016.

[69] J. Song, J. Huang, X. Chen et al., "Donor-derived exosomes induce specific regulatory $\mathrm{T}$ cells to suppress immune inflammation in the allograft heart," Scientific Reports, vol. 7, article no. 20077, 2016.

[70] V. Cantaluppi, S. Gatti, D. Medica et al., "Microvesicles derived from endothelial progenitor cells protect the kidney from ischemia-reperfusion injury by microRNA-dependent reprogramming of resident renal cells," Kidney International, vol. 82, no. 4, pp. 412-427, 2012.

[71] M. Monguió-Tortajada, R. Lauzurica-Valdemoros, and F. E. Borràs, "Tolerance in organ transplantation: from conventional immunosuppression to extracellular vesicles," Frontiers in Immunology, vol. 5, article 416, 2014.

[72] A. F. Christopher, R. P. Kaur, G. Kaur, A. Kaur, V. Gupta, and P. Bansal, "MicroRNA therapeutics: discovering novel targets and developing specific therapy," Perspectives in Clinical Research, vol. 7, no. 2, pp. 68-74, 2016.

[73] A. Bader and P. Lammers, "The therapeutic potential of microRNAs," Innovations in Pharmaceutical Technology, pp. 52-55, 2011. 


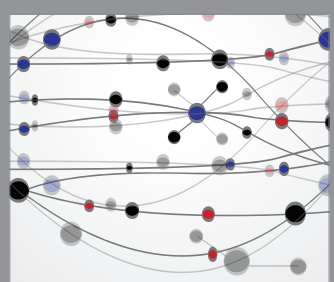

The Scientific World Journal
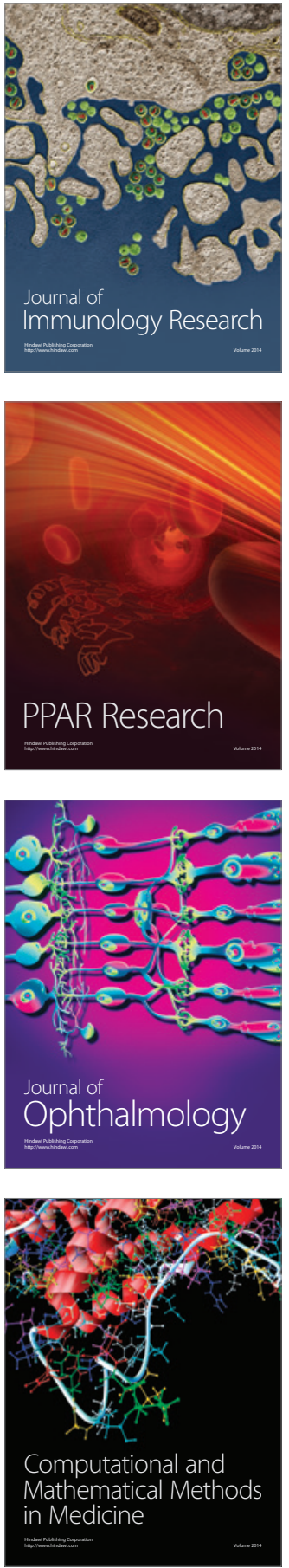

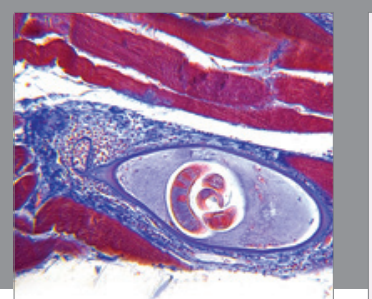

Gastroenterology Research and Practice
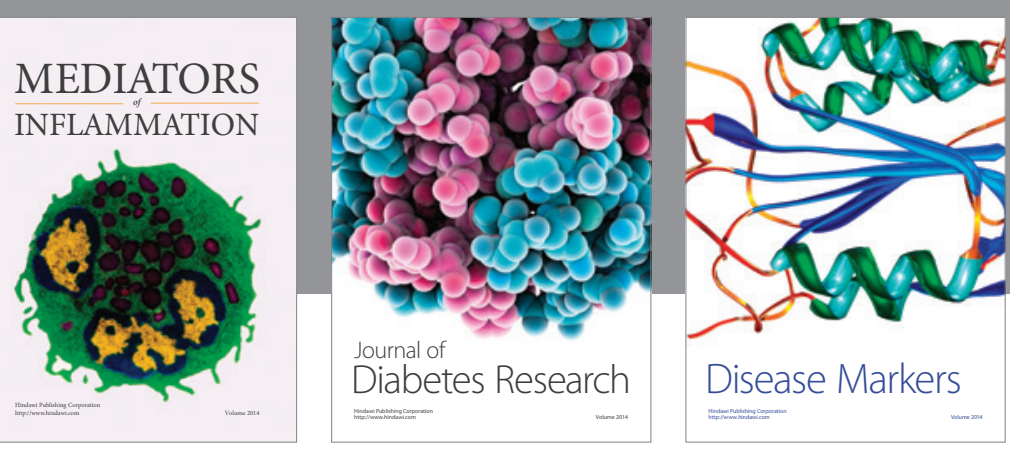

Disease Markers

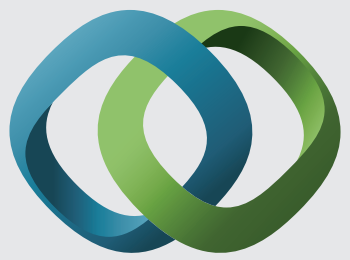

\section{Hindawi}

Submit your manuscripts at

https://www.hindawi.com
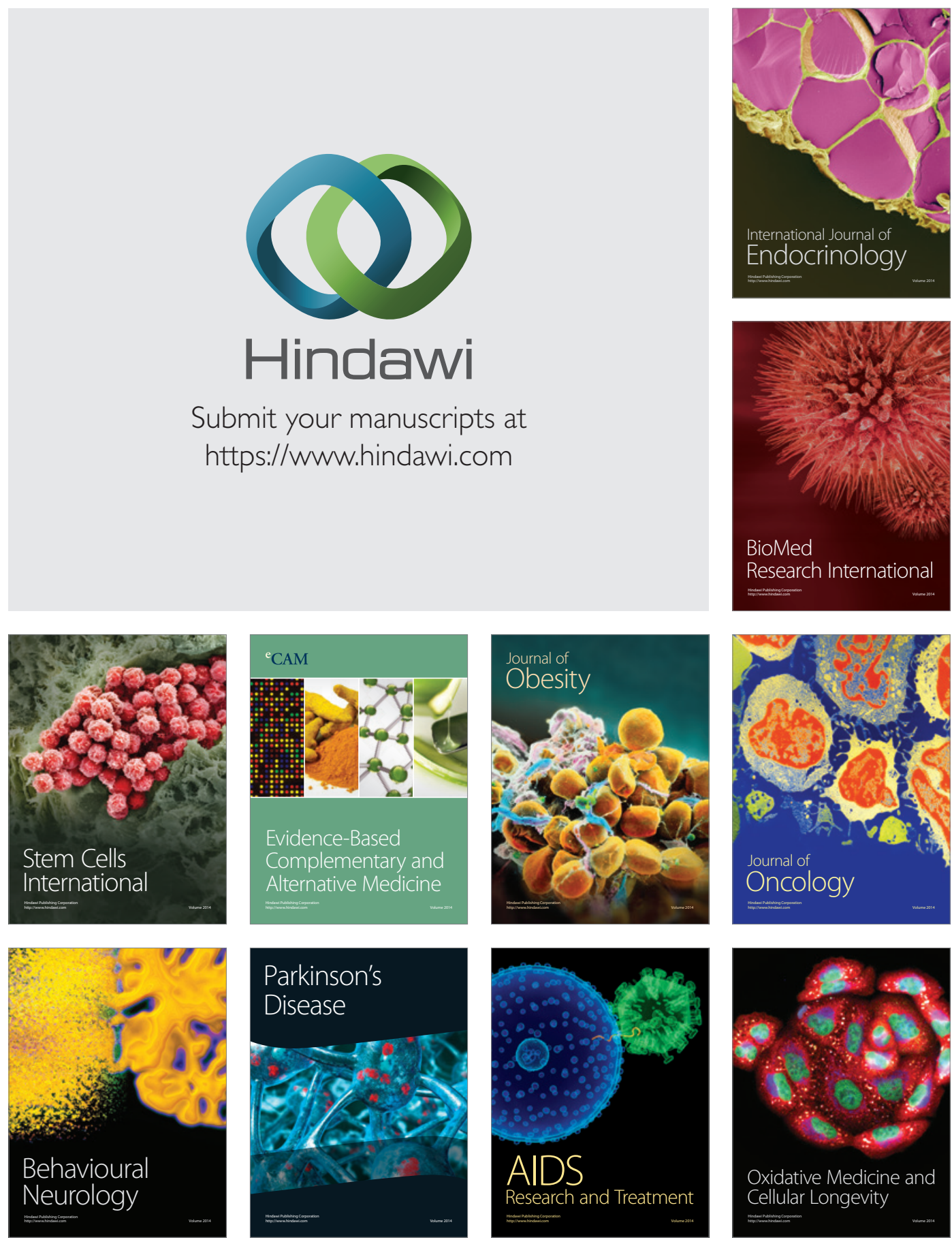